\title{
COVID-19 related stress exacerbates common physical and mental pathologies and affects treatment (Review)
}

\author{
KONSTANTINOS TSAMAKIS ${ }^{1,2}$, ANDREAS S. TRIANTAFYLLIS ${ }^{3}$, DIMITRIOS TSIPTSIOS ${ }^{4}$, \\ ELEFTHERIOS SPARTALIS ${ }^{5}$, CHRISTOPH MUELLER $^{2,6}$, CHARALAMPOS TSAMAKIS $^{7}$, SOFIA CHAIDOU $^{8}$, \\ DEMETRIOS A. SPANDIDOS ${ }^{9}$, LAMPROS FOTIS ${ }^{10}$, MARINA ECONOMOU ${ }^{11}$ and EMMANOUIL RIZOS ${ }^{1}$ \\ ${ }^{1}$ Second Department of Psychiatry, University of Athens, 'ATTIKON' University Hospital, 12462 Athens, Greece; \\ ${ }^{2}$ King's College London, Institute of Psychiatry, Psychology and Neuroscience, London SE5 8AF, UK; \\ ${ }^{3}$ Department of Cardiology, Asklepeion General Hospital, 16673 Athens, Greece; ${ }^{4}$ Department of Neurophysiology, \\ South Tyneside and Sunderland NHS Foundation Trust, Sunderland SR47TP, UK; ${ }^{5}$ 2nd Department of \\ Propaedeutic Surgery, National and Kapodistrian University of Athens School of Medicine, 11527 Athens, Greece; \\ ${ }^{6}$ South London and Maudsley NHS Foundation Trust, London SE5 8AZ; ${ }^{7}$ Department of Dermatology, \\ Luton and Dunstable University Hospital, Bedfordshire Hospitals NHS Foundation Trust, Luton LU4 0DZ, UK; \\ ${ }^{8} 1$ st Department of Paediatrics, University of Athens, Aghia Sophia Children's Hospital, 11527 Athens; \\ ${ }^{9}$ Laboratory of Clinical Virology, School of Medicine, University of Crete, 71003 Heraklion; ${ }^{10}$ Department of Paediatrics, \\ University of Athens, 'ATTIKON' University Hospital, 12462 Athens; ${ }^{11}$ Byron-Kessariani Community Mental Health \\ Centre, First Department of Psychiatry, University of Athens, 'EGINITION' Hospital, 11528 Athens, Greece
}

Received April 13, 2020; Accepted April 22, 2020

DOI: $10.3892 /$ etm.2020.8671

\begin{abstract}
COVID-19 pandemic has caused a global public health emergency resulting in unprecedented individual and societal fear and anxiety. The stress surrounding this biothreat appears to have clinical implications in all aspects of medicine, both in mental and physical health spheres. The impact of COVID-19 related anxiety in Cardiology, Paediatrics, Oncology, Dermatology, Neurology and Mental Health and how it affects treatments is discussed. Moreover, the need for introducing novel communication and therapeutic approaches is highlighted in the new landscape of the COVID-19 era.
\end{abstract}

\section{Contents}

1. Introduction

2. Mental health

3. Cardiology

4. Neurology

5. Oncology

6. Paediatrics

Correspondence to: Dr Konstantinos Tsamakis, Second Department of Psychiatry, University of Athens, 'ATTIKON' University Hospital, Rimini 1, Chaidari, 12462 Athens, Greece E-mail:ktsamakis@gmail.com

Key words: COVID-19, pandemic, physical and mental pathologies, stress, treatment, clinical implications
7. Dermatology

8. Conclusions

\section{Introduction}

COVID-19 continues its lethal spread globally (1) with detrimental effects on public health and social functioning $(2,3)$. Previous experience from smaller scale crises shows that they significantly affect the health and well-being of individuals (2). Clinical experience from our departments so far, in accordance with emerging literature, indicate that there is an association between stress surrounding COVID-19 pandemic and precipitation of various diseases, as well as their treatments.

\section{Mental health}

In any biological disaster fear, uncertainty and stigma prevail and they can act as barriers to proper psychiatric care (4). The distress and uncertainty caused by the lack of endpoint for the COVID-19 pandemic, while treatment is still not in sight, has a significant psychological impact on individuals. It can precipitate the emergence of psychopathology, such as depressive and anxiety disorders especially among vulnerable groups, for instance the elderly, including the particularly vulnerable ones from ethnic minority backgrounds (5), and people with pre-existing psychiatric or substance abuse problems (2).

Healthcare workers are at increased risk of psychiatric morbidities given the increased pressure they deal with (6). In particular, fear of contraction due to increased risk of exposure to virus, concerns about infecting their loved ones or having 
to isolate away from them and being involved in ethically difficult decisions around resource-allocation, may cause a significant psychological burden on them $(2,7,8)$; all this while working amid intense media and public scrutiny.

Furthermore, the lengthy, massive-scale, unprecedented social distancing and isolation that we are currently undergoing has additive implications; quarantine has been associated with negative psychological effects including emotional disturbance, depression, stress, low mood, irritability, panic attacks, phobic symptoms, insomnia, anger, emotional exhaustion and post-traumatic stress symptoms (9) and in extreme cases, suicide (10).

Finally, it is important to consider the stigma and discrimination towards infected people and their family members (11). Stigmatizing attitudes can present in many alternative versions and can be fueled by the fear of transmission of infectious diseases (12), therefore efforts to tackle the COVID-19 social stigma should be a priority amongst mental health professionals. Previous experience of the psychosocial impact of international outbreaks of viral epidemics and large scale financial crises, that COVID-19 is expected to trigger (13), underscore the urgent need to design and implement psychosocial support and intervention programs $(4,14)$; these should be considered an integral part of the healthcare strategy for the battle against COVID-19.

\section{Cardiology}

The brain-heart interaction has been long acknowledged as a significant factor for various cardiovascular diseases (15). Overstimulation of the sympathetic nervous system due to physical or emotional stressors has been hypothesized as the underlying cause of myocardialinfarction, hypertension, arrythmias and stress induced/Takotsubo cardiomyopathy (15-17).

COVID-19 pandemic has posed significant psychological strain on the community with emerging cardiovascular implications. Since our outpatient clinics are carried out solely by telecommunication, we have observed a continuous increase in telephone contacts from patients with cardiovascular history expressing distress and associated worsening of symptoms, in particular angina, palpitations and decompensation of heart failure (8). Very recent reports, have linked the huge emotional pressure caused by COVID-19 to stress induced/Takotsubo cardiomyopathy presenting as acute heart failure (18). Even though the number of myocardial infarctions would be anticipated to be high, given the increased anxiety and stimulation of the brain-heart axis, a decrease of almost $50 \%$ has been reported in Spain (19). However, other researchers alert that this finding most likely is unreal, underlying large delays in seeking medical help from patients suffering a myocardial infarction (20). Anxiety to confront SARS-CoV-2 refrains patients from visiting healthcare units. Patients are stressed and reluctant to be transferred to a COVID-19 hospital during the pandemic, which explains the potential delays in treatment for other medical problems. Some patients with myocardial infarction may not seek care at all, with detrimental consequences (20).

\section{Neurology}

Although direct, indirect and postinfectious neurological complications related to COVID-19 are well established (21), it is uncertain whether anxiety related to the recent pandemic affects neurological diseases. For the time being this does not seem to be the case. For example, stroke incidence is significantly decreased in the COVID-19 era $(22,23)$. Furthermore, in the case of migraine, recent experience from Italy showed that despite the fact that hospitals nowadays are considered non-secure places, patients suffering from severe migraine (who were under monthly treatment with IV medication) seemed to manage to overcome their fear of COVID-19, as they neglected the posed traffic restrictions by the government and made it to the hospital, in order to have their anti-migraine IV treatment administered (24). Thus, it seems that anxiety of migraine relapse outweighed anxiety related to COVID-19 pandemic (24). Finally, in the case of movement disorders, it is considered too early to conclude whether there will be long term impacts of COVID-19 pandemic on such patients (25). Although it is known that stress can unmask or worsen motor symptoms and accelerate the rate of dopaminergic cell loss, there are also factors that seem to offer protection against the detrimental effects of stress. This has been termed 'resilience', i.e., the ability to maintain or quickly recover mental health during and after times of adversity (26).

\section{Oncology}

The way we treat cancer during these unprecedented times is changing. The COVID-19 pandemic has not only changed our daily routines but also forced us to reconsider the approach to cancer patients. In the event of an overwhelming pandemic, many health care systems will implement a triage system that would potentially deny critical care treatment to some seriously ill patients (27). The novel pandemic has grounded several global activities including the provision of health care services to people with chronic conditions such as cancer. Current evidence suggests that cancer patients with COVID-19 infection are a vulnerable group, with a higher risk of severe illness resulting in intensive care unit admissions or death, particularly if they underwent surgery (28). According to the American Society of Clinical Oncology (ASCO), 'There is no direct evidence to support changes in cancer regimen during the pandemic' (29). Therefore, routinely stopping anticancer or immunosuppressive therapy is not recommended. Currently, there are cancellations or postponement of elective cancer surgeries and in the coming days radiotherapy appointments may also be affected. Newly diagnosed or existing patients with cancer who experience chest symptoms may be denied care, due to suspicion of COVID-19 infection. For patients with cancer, these will have huge repercussions on their experience and management of cancer-related symptoms, quality of life and survival.

Cancer patients are expectedly anxious whether they are symptomatic or not, which can sometimes negatively affect their genuine desire for life. They require information, counseling, symptomatic control and treatment. They need to be supported. Traditionally this is achieved through hospital visits, but in the new COVID-19 landscape, this could be potentially achieved by telemedicine; it is a matter of urgency that we accelerate remote cancer care, by also empowering patients and caregivers through effective communication. Furthermore, palliation remains an ethical obligation and we 
should strive for symptom control and comfort care especially during the pandemic (30).

\section{Paediatrics}

Recent data suggest that children are less susceptible to COVID-19 infection (31). However, given the large burden of anxiety passing from parents and media to children, considerable psychological implications have been noted. The lockdown of schools and playgrounds, the restriction of outdoor activities during physical and social isolation have been reported to trigger manifestations of anxiety, such as panic attacks and psychosomatic symptoms (8). Reports from China unveiled that the most common psychological and behavioral problems among children and adolescents were clinginess, distraction, irritability, and fear of asking questions about the epidemic (32). It is also important to note that the social isolation and the exhortation to 'stay at home' has major implications for those children already living in the same household with someone who is abusive; unfortunately, domestic violence rates are rising fast (33).

Reports on the response of the pediatric population during pandemics remain scarce. Psychological stress in children may cause anxiety, depression, lethargy, impaired social interaction and reduced appetite. Physiological effects include a weakened or compromised immune system leading to increased susceptibility to other diseases (32). Communication with children to express their concerns, playing collaborative games to alleviate loneliness, encouraging physical activity and using music therapy can reduce psychological stress (32).

Pediatric patients and especially adolescents receiving immunomodulatory treatment for autoimmune disorders express concerns for their safety during the pandemic. Our experience is that a proportion of them has discontinued treatment on their own accord, because of their fear and uncertainty about potential risks related to COVID-19. However, the limited available data do not support this; in a series of children receiving immunosuppression post-organ transplantation, despite acquiring COVID-19, none of them became seriously ill (34).

\section{Dermatology}

The anxiety associated with the actual COVID-19 infection, as well as with the isolation and social distancing that people have to experience due to the pandemic, can be a potential cause for exacerbation of several chronic inflammatory skin conditions, especially those which are stress induced, like psoriasis, atopic dermatitis, rosacea and urticaria (35). Medication adherence, especially in psoriasis has been challenging (36), and could potentially deteriorate in the midst of the current COVID-19 panic and misinformation in the social media (37), therefore providing clear guidance through efficient patient-clinician communication is of critical importance.

Dermatologists need to remain alert and mindful of the significance of COVID-19. Special consideration should be given to high-risk patients with disease exacerbations, especially those on immunomodulatory medications (37). Clinicians should try to arrange safe monitoring, whilst at the same time avoiding unnecessary hospital visits. There is a need for accelerating the implementation of tele-dermatology, which has been shown to be effective (37).

\section{Conclusions}

The consequences of COVID-19 pandemic are multifaceted. The enormous individual and societal anxiety caused by this biothreat affects a wide spectrum of physical and mental pathologies and may even hamper their treatment. Remaining alert over the impact of the pandemic, retaining effective communication between clinicians of different specialties and patients, as well as introducing novel ways of clinical interaction such as telemedicine, can assist to overcome the mounting challenges of the COVID-19 pandemic.

\section{Acknowledgements}

Not applicable.

\section{Funding}

No funding was received.

\section{Availability of data and materials}

Not applicable.

\section{Authors' contributions}

KT and AST wrote the original draft, edited and critically revised the manuscript. DT, ES, ME, CT, SC, LF contributed substantially in the writing of the manuscript, and critically revised and edited the manuscript. ER, DAS and CM critically revised and edited the manuscript. All authors substantially contributed to the conception, writing and revision of the work and approved the final content of the manuscript.

\section{Ethics approval and consent to participate}

Not applicable.

\section{Patient consent for publication}

Not applicable.

\section{Competing interests}

DAS is the Editor-in-Chief for the journal, but had no personal involvement in the reviewing process, or any influence in terms of adjudicating on the final decision, for this article. The other authors declare that they have no competing interests.

\section{References}

1. Docea AO, Tsatsakis A, Albulescu D, Cristea O, Zlatian O, Vinceti M, Moschos SA, Tsoukalas D, Goumenou M, Drakoulis N, Dumanov JM, et al: A new threat from an old enemy: Re-emergence of coronavirus (Review). Int J Mol Med: Mar 27, 2020 (Epub ahead of print).

2. Pfefferbaum B and North CS: Mental health and the Covid-19 pandemic. N Engl J Med: Apr 13, 2020 (Epub ahead of print). 
3. Ahmad A, Mueller C and Tsamakis K: Covid-19 pandemic: A public and global mental health opportunity for social transformation? BMJ 369: $\mathrm{m} 1383,2020$.

4. Xiang YT, Yang Y, Li W, Zhang L, Zhang Q, Cheung T and $\mathrm{Ng} \mathrm{CH}$ : Timely mental health care for the 2019 novel coronavirus outbreak is urgently needed. Lancet Psychiatry 7: 228-229, 2020.

5. Mansour R, Tsamakis K, Rizos E, Perera G, Das-Munshi J, Stewart R and Mueller C: Late-life depression in people from ethnic minority backgrounds: Differences in presentation and management. J Affect Disord 264: 340-347, 2020.

6. Lai J, Ma S, Wang Y, Cai Z, Hu J, Wei N, Wu J, Du H, Chen T, Li R, et al: Factors associated with mental health outcomes among health care workers exposed to coronavirus disease 2019. JAMA Netw Open 3: e203976, 2020.

7. Kang L, Li Y, Hu S, Chen M, Yang C, Yang BX, Wang Y, Hu J, Lai J, Ma X, et al: The mental health of medical workers in Wuhan, China dealing with the 2019 novel coronavirus. Lancet Psychiatry 7: e14, 2020.

8. Tsamakis K, Rizos E, Manolis AJ, Chaidou S, Kympouropoulos S, Spartalis E, Spandidos DA, Tsiptsios D and Triantafyllis AS: [Comment] COVID-19 pandemic and its impact on mental health of healthcare professionals. Exp Ther Med 19: 3451-3453, 2020.

9. Brooks SK, Webster RK, Smith LE, Woodland L, Wessely S, Greenberg N and Rubin GJ: The psychological impact of quarantine and how to reduce it: Rapid review of the evidence. Lancet 395: 912-920, 2020.

10. Barbisch D, Koenig KL and Shih FY: Is there a case for quarantine? Perspectives from SARS to Ebola. Disaster Med Public Health Prep 9: 547-553, 2015.

11. Fiorillo A and Gorwood P: The consequences of the COVID-19 pandemic on mental health and implications for clinical practice. Eur Psychiatry 63: e32, 2020.

12. Economou M, Dieti $\mathrm{E}$ and Lazaratou $\mathrm{H}$ : Alternative versions of stigma: Attitudes of the Greek public toward refugees amid economic recession. Eur Arch Psychiatry Clin Neurosci 268 213-214, 2018.

13. Center for Global Development: How COVID-19 Could Be Like the Global Financial Crisis (Or Worse). https://www.cgdev.org/blog/ how-covid-19-could-be-global-financial-crisis-or-worse. Accessed March 18, 2020.

14. Economou M, Angelopoulos E, Peppou LE, Souliotis K, Tzavara C, Kontoangelos K, Madianos M and Stefanis C: Enduring financial crisis in Greece: Prevalence and correlates of major depression and suicidality. Soc Psychiatry Psychiatr Epidemiol 51: 1015-1024, 2016.

15. Jiang W, Babyak M, Krantz DS, Waugh RA, Coleman RE, Hanson MM, Frid DJ, McNulty S, Morris JJ, O'Connor CM and Blumenthal JA: Mental stress-induced myocardial ischemia and cardiac events. JAMA 275: 1651-1656, 1996.

16. Dagres N, Triantafyllis A and Anastasiou-Nana M: Picture quiz. A 70 year old woman with chest pain after a stressful event. BMJ 347: f5583, 2.13

17. Templin C, Hänggi J, Klein C, Topka MS, Hiestand T, Levinson RA, Jurisic S, Lüscher TF, Ghadri JR and Jäncke L: Altered limbic and autonomic processing supports brain-heart axis in Takotsubo syndrome. Eur Heart J 40: 1183-1187, 2019.

18. Meyer P, Degrauwe S, Delden CV, Ghadri JR and Templin C: Typical takotsubo syndrome triggered by SARS-CoV-2 infection. Eur Heart J: April 14, 2020 (Epub ahead of print).

19. Rodríguez-Leor O, Cid-Álvarez B, Ojeda S, Martín-Moreiras J, Ramón Rumoroso J, López-Palop R, Serrador A, Romaguera R, Cruz I, de Prado AP, et al: Impacto de la pandemia de COVID-19 sobre la actividad asistencial en cardiología intervencionista en España. REC Interv Cardiol: April 16, 2020 (Epub ahead of print) (In Spanish).

20. Tam CF, Cheung KS, Lam S, Wong A, Yung A, Sze M, Lam YM, Chan C, Tsang TC, Tsui M, et al: Impact of coronavirus disease 2019 (COVID-19) outbreak on ST-segment-elevation myocardial infarction care in Hong Kong, China. Circ Cardiovasc Qual Outcomes: March 17, 2020 (Epub ahead of print).
21. Pérez CA: Looking ahead: The risk of neurologic complications due to COVID-19. Neurol Clin Pract: April 9, 2020 (Epub ahead of print).

22. Baracchini C, Pieroni A, Viaro F, Cianci V, Cattelan AM, Tiberio I, Munari M and Causin F: Acute stroke management pathway during Coronavirus-19 pandemic. Neurol Sci: April 9, 2020 (Epub ahead of print).

23. Morelli N, Rota E, Terracciano C, Immovilli P, Spallazzi M, Colombi D, Zaino D, Michieletti E and Guidetti D: The baffling case of ischemic stroke disappearance from the Casualty Department in the COVID-19 era. Eur Neurol: April 14, 2020 (Epub ahead of print).

24. Silvestro M, Tessitore A, Tedeschi G and Russo A: Migraine in the time of COVID-19. Headache: Apr 8, 2020 (Epub ahead of print).

25. Papa SM, Brundin P, Fung VSC, Kang UJ, Burn DJ, Colosimo C, Chiang HL, Alcalay RN and Trenkwalder C; MDS-Scientific Issues Committee: Impact of the COVID-19 pandemic on Parkinson's disease and movement disorders. Mov Disord: Apr 6 , 2020 (Epub ahead of print)

26. Helmich RC and Bloem BR: The impact of the COVID-19 pandemic on Parkinson's disease: hidden sorrows and emerging opportunities. J Parkinsons Dis 10: 351-354, 2020.

27. Downar J and Seccareccia D; Associated Medical Services Inc. Educational Fellows in Care at the End of Life: Palliating a pandemic: 'All patients must be cared for'. J Pain Symptom Manage 39: 291-295, 2010.

28. Liang W, Guan W, Chen R, Wang W, Li J, Xu K, Li C, Ai Q, $\mathrm{Lu} \mathrm{W}$, Liang $\mathrm{H}$, et al: Cancer patients in SARS-CoV-2 infection: A nationwide analysis in China. Lancet Oncol 21: 335-337, 2020.

29. American Society of Clinical Oncology: COVID-19 Patient Care Information. https://www.asco.org/asco-coronavirus-information/care-individuals-cancer-during-covid-19. Updated April 9, 2020

30. Salako O, Okunade K, Allsop M, Habeebu M, Toye M, Oluyede G, Fagbenro G and Salako B: Upheaval in cancer care during the COVID-19 outbreak. Ecancermedicalscience 14: ed97, 2020.

31. Lu X, Zhang L, Du H, Zhang J, Li YY, Qu J, Zhang W, Wang Y, Bao S, Li Y, et al: SARS-CoV-2 infection in children. $\mathrm{N}$ Engl J Med: March 18, 2020 (Epub ahead of print).

32. Jiao WY, Wang LN,Liu J,Fang SF, JiaoFY,Pettoello-Mantovani M and Somekh E: Behavioral and emotional disorders in children during the COVID-19 epidemic. J Pediatr: April 2, 2020 (Epub ahead of print).

33. Bradbury-Jones $C$ and Isham L: The pandemic paradox: the consequences of COVID-19 on domestic violence. J Clin Nurs: Apr 12, 2020 (Epub ahead of print).

34. D'Antiga L: Coronaviruses and immunosuppressed patients. The facts during the third epidemic. Liver Transpl: Mar 20, 2020 (Epub ahead of print).

35. Kutlu Ö and Metin A: A case of exacerbation of psoriasis after oseltamivir and hydroxychloroquine in a patient with COVID-19: Will cases of psoriasis increase after COVID-19 pandemic? Dermatol Ther: April 7, 2020 (Epub ahead of print).

36. Wang W, Qiu Y, Zhao F and Zhang F: Poor medication adherence in patients with psoriasis and a successful intervention. J Dermatolog Treat 30: 525-528, 2019.

37. Chawla S: COVID-19: Challenges and opportunities for dermatology response. J Dermatolog Treat: April 14, 2020 (Epub ahead of print).

This work is licensed under a Creative Commons Attribution-NonCommercial-NoDerivatives 4.0 International (CC BY-NC-ND 4.0) License. 